Jurnal Natur Indonesia 15(1), Februari 2013: 9-14

ISSN 1410-9379

\title{
Keanekaragaman Spesies Parasitoid Telur Hama Lepidoptera dan Parasitisasinya pada Beberapa Tanaman di Kabupaten Solok, Sumatera Barat
}

\author{
Hidrayani*), R. Rusli, dan Y. S. Lubis \\ Jurusan Hama dan Penyakit Tumbuhan, Fakultas Pertanian, Universitas Andalas, Kampus Limau Manis, Padang 25163 \\ Diterima 26-05-2011Ｄisetujui 04-012-2012
}

\begin{abstract}
A study was conducted to determine the species diversity of lepidoptera egg parasitoids on several crops in Solok. lepidopteran eggs were collected from rice, corn, tomato, and cabbage. A survey was conducted by using Stratified Purposive Sampling Method. Two districts (Gunung Talang and Lembah Gumanti) were chosen as centre of the target crops. The results showed that five species of egg parasitoids were found parasitizing lepidopteran eggs. The species found on rice were Telenomus sp., Tetrastichus sp., and Trichogramma japonicum parasitizing Scirpophaga incertulas and Hesperiidae with parasitization levels were 29.54; 13.02; and 2.05\% respectively. The species found on corn was Trichogrammatoidea spp. parasitizing Helicoverpa armigera with parasitization level was $29.07 \%$. None of parasitoid was found to parasitize eggs of $H$. armigera on tomato. The egg parasitoid parasitizing Crocidolomia pavonana and Spodoptera litura on cabbage was Trichogramma chilotrae with parasitization level was $1.67 \%$. The most abundance species of lepidopteran egg parasitoids were Telenomus sp.and Trichogrammatoidea sp. The diversity index of egg parasitoids on rice in different sample areas varied from 0.46 to 0.63 based on Simpsons index. It indicated that the species diversity of lepidopteran eggs was relatively low.
\end{abstract}

Keywords: diversity, egg parasitoid, lepidopteran pest

\begin{abstract}
ABSTRAK
Penelitian dilakukan untuk mempelajari keanekaragaman spesies parasitoid telur pada beberapa tanaman di Kabupaten Solok. Telur lepidoptera dikumpulkan dari tanaman padi, jagung, tomat, dan kubis. Survei dilakukan di dua kecamatan (Gunung Talang dan Lembah Gumanti) dengan menggunakan metode Stratified Purposive Sampling. Hasil menunjukkan bahwa terdapat lima spesies parasitoid yang bersifat parasit pada telur lepidoptera pada tanaman tersebut di atas. Parasitoid Telenomus sp., Tetrastichus sp., dan Trichogramma japonicum ditemukan menginfeksi telur Scirpophaga incertulas dan hesperiidae dengan tingkat parasitisasi masing-masing 29,54; 13,02; dan 2,05\%. Trichogrammatoidea sp. ditemukan menginfeksi telur Helicoverpa armigera pada tanaman jagung dengan tingkat parasitisasi 29,07\%. Tidak ditemukan parasitoid yang menginfeksi Helicoverpa armigera pada tanaman tomat. Trichogramma chilotrae ditemukan menginfeksi Crocidolomia pavonana dan Spodoptera litura pada tanaman kubis dengan tingkat parasitisasi 1,67\%. Kelimpahan parsitoid telur hama lepidoptera tertinggi terdapat pada spesies Telenomus sp. dan Trichogrammatoidea sp. Index keanekaragaman parasitoid telur pada tanaman padi pada berbagai lokasi bervariasi dari 0,46 sampai 0,63 berdasarkan indeks Simpsons. Hal ini menunjukkan bahwa keanekaragaman spesies parasitoid telur masih relatif rendah.
\end{abstract}

Kata Kunci: hama lepidoptera, keanekaragaman, parasitoid telur

\section{PENDAHULUAN}

Tanaman padi (Oriza sativa), jagung (Zea mays), tomat (Lycopersicon esculentum) dan kubis (Brassica oleracea) dibudidayakan secara luas di Indonesia. Upaya untuk meningkatkan produksi tanaman tersebut masih mengalami beberapa kendala salah satunya adalah serangan hama tanaman. Lepidoptera adalah salah satu ordo yang sering menyebabkan kerusakan yang berarti pada hama penggerek batang padi, hama penggerek tongkol jagung, hama buah tomat, dan ulat krop pada daun kubis (Kalshoven 1981).

\footnotetext{
*Telp: +6281266148366

Email: hidrayani@yahoo.com
} 
Serangan Helicoverpa armigera biasanya terjadi pada musim kemarau yang dapat mengakibatkan kehilangan hasil panen sebesar $52 \%$ pada tanaman tomat dan $67 \%$ pada jagung (Setiawati 1991). Serangan ulat krop pada daun kubis dapat mengakibatkan kehilangan hasil sampai $100 \%$.

Untuk pengendalian serangan hama tersebut, petani masih menggunakan insektisida sintetik yang diketahui menimbulkan banyak dampak negatif. Untuk itu perlu pengendalian alternatif yang ramah lingkungan, di antaranya adalah pengendalian hayati yang merupakan salah satu komponen Pengendalian Hama Terpadu (PHT). Pengendalian hayati adalah pengendalian dengan memanfaatkan musuh alami yang salah satunya parasitoid yang banyak memberikan keuntungan karena selain aman terhadap lingkungan juga dapat berkembang secara alami dan dalam hal tertentu efektif menekan perkembangan populasi hama (Nurtiati 1991).

Parasitoid telur sebagai agen pengendalian hayati saat ini mendapat perhatian yang serius terutama dalam kaitannya dengan pengembangan teknologi alternatif pengendalian hama (Ahmad et al. 2012, Pabbage \& Tandiabang 2007, Mandaor et al. 2012). Keuntungan menggunakan parasitoid telur yaitu dapat mengendalikan populasi hama pada stadium awal. Parasitoid telur seperti Trichogramma sp. dan Trichogrammatoidea sp. yang tergolong ke dalam famili Trichogrammatidae mempunyai peluang yang sangat besar untuk dapat dimanfaatkan karena selain kemampuan mengendalikan populasi hama pada stadium awal, juga bersifat polifag, dan mudah dikembangbiakkan pada inang pengganti.

Sejauh ini di Indonesia telah dilaporkan lebih kurang 15 spesies Trichogrammatidae (Buchori et al. 2002) dan di Pulau Jawa dilaporkan terdapat lima spesies yang tergolong pada genus Trichogramma dan Trichogrammatoidea (Buchori et al. 2010). Kajian parasitoid telur di Sumatera Barat baru berada pada tahap awal (Hidrayani et al. 2007) sehingga perlu dilanjutkan agar dapat dimanfaatkan sebagai agen hayati yang potensial. Mengingat Kabupaten Solok merupakan sentra produksi padi, jagung, tomat dan kubis, dirasa sangat perlu untuk dilakukan kajian tentang berbagai parasitoid telur yang menginfeksi hama lepidoptera yang menyerang tanaman tersebut. Perbedaan serangga inang, tanaman dan lokasi mungkin menyebabkan keanekaragaman jenis dan parasitisasi parasitoid. Penelitian telah dilakukan dengan tujuan untuk mempelajari keanekaragaman spesies parasitoid telur yang menginfeksi berbagai spesies hama lepidoptera dan parasitisasinya pada tanaman padi, jagung, tomat, dan kubis di Kabupaten Solok.

\section{METODE PENELITIAN}

Penentuan Daerah Sampel. Penelitian berbentuk survei dengan menggunakan metode Stratified Purposive Sampling yang dilakukan di Kabupaten Solok dengan mengambil 2 kecamatan yaitu Kecamatan Lembah Gumanti dan Kecamatan Gunung Talang. Di Kecamatan Lembah Gumanti diambil pada Kenagarian Alahan Panjang dan Sungai Nanam yang merupakan daerah sentra produksi kubis dan tomat. Di Kecamatan Gunung Talang diambil pada Kenagarian Talang, Koto Gaek, dan Jawi-jawi yang merupakan daerah sentra produksi padi dan jagung. Untuk masing-masing kenagarian diambil 2 hamparan, dan dari masing-masing hamparan diambil petakan dengan luas $\pm 400 \mathrm{~m}^{2}$. Telur-telur hama lepidoptera dikumpulkan dari tanaman yang terdapat di sepanjang diagonal petakan.

Pengumpulan Telur Lepidoptera. Telur lepidoptera dikumpulkan dari bagian tanaman tempat telur diletakkan, kemudian dimasukkan ke dalam tabung reaksi, ditutup dengan kapas, dan diberi label.

Pemeliharaan Telur Lepidoptera. Telur hama lepidoptera kemudian dihitung jumlahnya dan selanjutnya dipelihara sampai imago parasitoid muncul atau sampai telur menetas bila tidak terparasit. Parasitoid yang muncul kemudian dihitung dan dimasukkan ke dalam alkohol $70 \%$ untuk selanjutnya diidentifikasi. Untuk menghitung jumlah telur penggerek batang dilakukan dengan perendaman kelompok telur tersebut di dalam larutan $\mathrm{KOH}$ selama \pm 24 jam dan setelah itu telur-telur tersebut dapat dihitung dengan mudah dengan bantuan mikroskop binokuler.

Identifikasi Parasitoid Telur. Identifikasi parasitoid telur Trichogrammatidae dilakukan di Departemen Proteksi Tanaman, Institut Pertanian Bogor. Identifikasi parasitoid Telenomus dan Tetrastichus dilakukan di Laboratorium Biologi Politeknik Pertanian Universitas Andalas, Payakumbuh dengan referensi Yuliarti (2002).

Jenis dan Jumlah Telur Hama Lepidoptera dan Parasitoidnya. Telur-telur hama lepidoptera yang telah dikumpulkan di lapangan, ditentukan jenis dan jumlah telur hama per petak $\left( \pm 400 \mathrm{~m}^{2}\right)$ serta jenis dan jumlah parasitoid yang menginfeksi telur-telur hama tersebut .

Tingkat Parasitisasi. Tingkat parasitisasi dari masingmasing spesies parasitoid dihitung dengan menggunakan rumus: 


$$
\mathrm{P}=\frac{\mathrm{n}}{\mathrm{N}} \times 100 \%
$$

$\mathrm{P}=$ tingkat parasitisasi

$\mathrm{n}=$ jumlah telur lepidoptera yang terparasit

$\mathrm{N}=$ jumlah telur lepidoptera yang diamati

Indeks Keanekaragaman Spesies Parasitoid Telur. Indeks keanekaragaman spesies parasitoid telur ditentukan dengan menggunakan rumus Indeks Keanekaragaman Simpsons (Krebs 1999).

$$
\mathrm{D}=\sum_{\mathrm{i}=1}^{\mathrm{S}} \mathrm{Pi}^{2}
$$

$\mathrm{D}=$ indeks keanekaragaman simpsons

$\mathrm{S}=$ jumlah spesies parasitoid telur

$\mathrm{P}_{\mathrm{i}}=$ proporsi spesies parasitoid telur terhadap total populasi

\section{HASIL DAN PEMBAHASAN}

Jenis dan Jumlah Telur Hama Lepidoptera. Terdapat telur dari lima spesies hama lepidoptera yang menyerang berbagai tanaman di Kabupaten Solok dengan populasi yang bervariasi (Tabel 1). Pada tanaman padi kepadatan telur hama penggerek batang padi kuning, Scirpophaga incertulas lebih tinggi $\left(12,25\right.$ kelompok telur/400 $\left.\mathrm{m}^{2}\right)$ dibanding telur Hesperidae (3,75 kelompok telur/400 m²). Di seluruh daerah sampel, terdapat kecenderungan yang sama (Gambar 1). Namun kedua jenis hama ditemukan pada setiap lokasi sampel, yang berarti bahwa kedua jenis hama tersebut telah merata menyebar di Kabupaten Solok. Akan tetapi populasi kedua jenis hama tersebut tergolong rendah. Rendahnya populasi hama lepidoptera ini diduga disebabkan oleh peranan musuh alami seperti predator, terutama jenis laba-laba yang banyak ditemukan di daerah sampel. Laba-laba mampu menekan populasi penggerek batang padi sekitar 55-87\% (Pracaya 1999).

Pada jagung dan tomat terdapat telur dari spesies hama yang sama yaitu telur Helicoverpa armigera, tetapi populasinya pada tanaman jagung lebih tinggi (36-53 butir/ $400 \mathrm{~m}^{2}$ ) dibanding tomat (18-27 butir/400 m²) (Tabel 2 dan 3). Namun, populasi telur $H$. armigera pada kedua jenis tanaman tersebut tergolong rendah. Kemungkinan pada jagung, tidak begitu luas ditanam sehingga mengakibatkan makanan bagi hama menjadi berkurang, akibatnya populasi tidak berkembang. Makanan merupakan faktor yang penting bagi serangga hama (Untung 1993). Alasan lainnya, kemungkinan varietas jagung yang ditanam kurang atau tidak disukai oleh $H$. armigera atau kemungkinan juga musuh alami yang ada di tanaman jagung dapat berfungsi dengan baik disebabkan tanaman jagung tidak disemprot pestisida dengan intensif.

Rendahnya populasi lepidoptera pada tanaman tomat erat kaitannya dengan penggunaan insektisida yang intensif sehingga dapat menekan populasi $H$. armigera. Petani di Kecamatan Lembah Gumanti Solok umumnya masih menggunakan pestisida yang intensif dalam mengendalikan

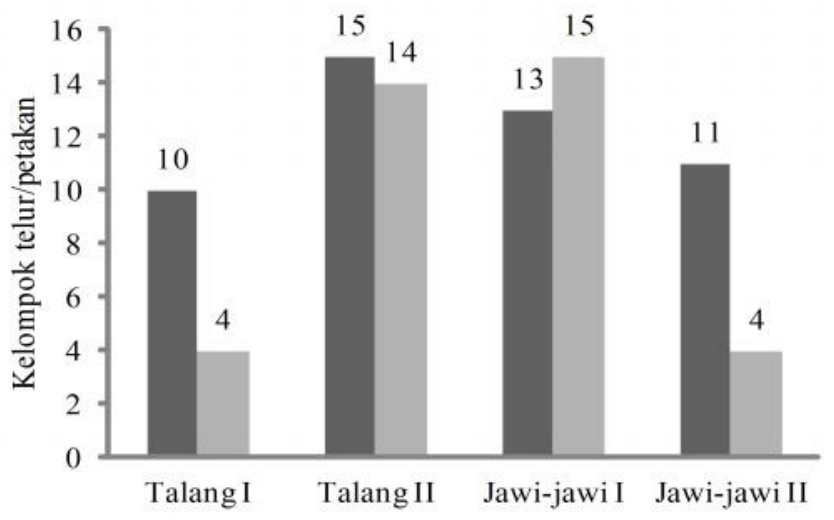

- $S$. intercules

Hesperidae

Lokasi

Gambar 1 Kepadatan populasi kelompok telur hama lepidoptera pada tanaman padi di berbagai lokasi di Kabupaten Solok

Tabel 2 Kepadatan populasi telur H. armigera pada tanaman jagung di Kabupaten Solok

\begin{tabular}{lc}
\hline Hamparan & Populasi (Butir telur $\left./ 400 \mathrm{~m}^{2}\right)$ \\
\hline Koto Gaek 1 & 44,00 \\
Koto Gaek 2 & 36,00 \\
Talang 1 & 50,00 \\
Talang 2 & 53,00 \\
Rata-rata & 45,75 \\
\hline
\end{tabular}

Tabel 3 Kepadatan populasi telur $H$. armigera pada tanaman tomat di Kabupaten Solok

\begin{tabular}{lc}
\hline \multicolumn{1}{c}{ Hamparan } & Populasi (Butir telur $\left./ 400 \mathrm{~m}^{2}\right)$ \\
\hline Sungai Nanam 1 & 20,00 \\
Sungai Nanam 2 & 27,00 \\
Alahan Panjang 1 & 18,00 \\
Alahan Panjang 2 & 20,00 \\
Rata-rata & 21,25 \\
\hline
\end{tabular}

Tabel 1 Jenis dan jumlah telur hama lepidoptera per petak pada beberapa tanaman di Kabupaten Solok

\begin{tabular}{lcrr}
\hline Tanaman & Jenis hama & \multicolumn{2}{c}{ Jumlah telur/400 m $^{2}$} \\
\cline { 2 - 4 } Padi & Scirpophaga incertulas & 12,25 & Butir telur \\
& Hesperidae & 3,75 & 1325,75 \\
Jagung & Helicoverpa armigera & - & 581,00 \\
Tomat & Helicoverpa armigera & - & 21,75 \\
Kubis & Crocidolomia pavonana & 14,75 & 851,50 \\
& Spodoptera litura & 1,50 & 254,25 \\
\hline
\end{tabular}


hama maupun penyakit yang menyerang pertanaman terutama tomat dan kubis (Ali et al. 1997; Rusli 2002). Hal ini juga ditambahkan oleh Budiman (2004) bahwa cara pengendalian hama yang umum dilakukan petani di Alahan Panjang adalah dengan insektisida.

Telur lepidoptera yang ditemukan pada kubis adalah Crocidolomia pavonana dan Spodoptera litura, tetapi populasi $C$. pavonana lebih tinggi (14,75 kelompok telur/ $\left.400 \mathrm{~m}^{2}\right)$ dibanding $S$. litura $\left(1,5\right.$ kelompok telur/400 $\left.\mathrm{m}^{2}\right)$. Kecenderungan ini terlihat pada semua lokasi pengambilan sampel (Gambar 2). C. pavonana merupakan hama utama tanaman kubis dan selalu ada pada pertanaman. Bila tidak dikendalikan, maka hama tersebut bisa menimbulkan kerugian sampai $100 \%$ (Sastrosiswojo 1996). Kajian yang dilakukan oleh Hidrayani et al. (2006) juga menunjukkan bahwa serangan $C$. pavonana lebih tinggi pada kubis bunga dibanding hama lainnya.

Parasitoid Telur Lepidoptera. Terdapat lima spesies parasitoid telur hama lepidoptera yang ditemukan di Kabupaten Solok, yaitu Telenomus sp. (Hymenoptera: Scelilionidae), Tetrastichus sp. (Hymenoptera : Eulophidae), Trichogramma japonicum Ashm (Hymenoptera: Trichogrammatidae), Trichogrammatoidea sp. (Hymenoptera: Trichogrammatidae) dan Trichogramma chilotrae Nag.\&Nag. (Hymenoptera : Trichogrammatidae) dengan tingkat parasitisasi yang bervariasi (Tabel 4).

Pada tanaman padi ditemukan tiga jenis parasitoid telur, yaitu Telenomus sp., Tetrastichus sp. dan T. japonicum yang menginfeksi kedua jenis telur lepidoptera, S. incertulas dan Hesperidae. Parasitoid telur dominan ditemukan adalah Telenomus sp. dengan tingkat parasitisasi rata-rata 29,54\%, kemudian diikuti oleh Tetrastichus sp. $(13,02 \%)$ dan $T$. japonicum $(2,05 \%)$. Kecenderungan angka ini terdapat di

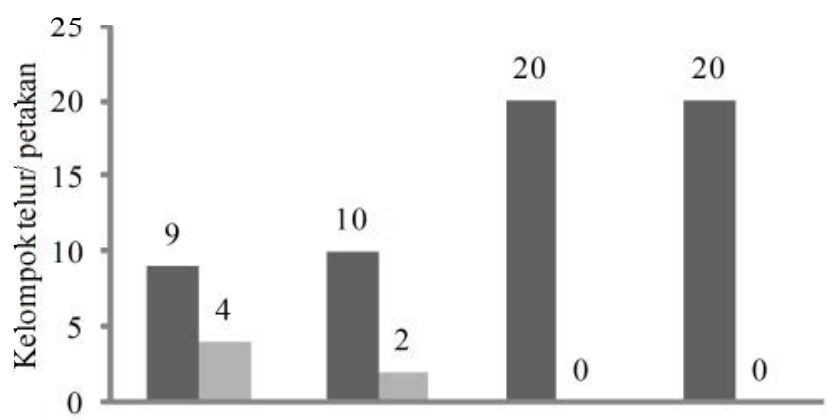

Al. Panjang I Al. Panjang II S. Nanam I S. Nanam II

C. pavonana

Lokasi

- S. litura

Gambar 2 Populasi kelompok telur hama lepidoptera pada tanaman kubis di Kecamatan Lembah Gumanti Kabupaten Solok semua daerah sampel. Walaupun parasitoid telur Tetrastichus sp. dan T. japonicum kurang dominan, tetapi bila dijumlahkan untuk ketiga jenis parasitoid, maka tingkat parasitisasinya mencapai rata-rata $44,61 \%$. Hal ini menunjukkan bahwa keanekaragaman jenis parasitoid sangat dibutuhkan untuk menekan perkembangan hama di lapangan yang berarti bahwa bila parasitoid bekerja dalam komunitas, maka parasitoid dapat meningkatkan unjuk kerjanya. Beranekaragamnya parasitoid telur yang ditemukan merupakan salah satu jawaban terhadap rendahnya populasi hama lepidoptera pada tanaman padi di daerah survei selain keberadaan komunitas predator.

Indeks keanekaragaman parasitoid pada tanaman padi di berbagai lokasi sampel bervariasi dari 0,47 sampai 0,63 dengan rata-rata 0,54 (Tabel 5). Hal ini mengindikasikan bahwa keanekaragaman parasitoid telur lepidoptera pada tanaman padi di daerah Solok tidak begitu berbeda dan relatif rendah. Jenis parasitoid telur yang ditemukan di masingmasing hamparan hampir sama, tetapi jumlah individunya yang berbeda. Rendahnya keanekaragaman ini diduga dipengaruhi oleh sistem pertanian yang monokultur. Ekosistem pertanian monokultur mempunyai kekayaan dan kelimpahan musuh alami yang lebih rendah dibanding pada tanaman polikultur (Yaherwandi 2005).

Pada pengamatan terhadap telur penggerek tongkol jagung H.armigera ditemukan hanya satu jenis parasitoid telur Trichogrammatoidea sp. dengan tingkat parasitisasi berkisar dari 25-33,93\% dengan rata-rata 29,07\% (Tabel 6). Akan tetapi pada telur $H$. armigera yang menyerang tomat, tidak ditemui adanya parasitoid.

Pada tanaman kubis ditemukan parasitoid telur Trichogramma chilotrae pada telur C. pavonana dan S. litura, tetapi tidak ditemukan di semua daerah sampel.

Tabel 4 Tingkat parasitisasi parasitoid telur lepidoptera pada beberapa tanaman di Kabupaten Solok

\begin{tabular}{llc}
\hline Tanaman & Jenis parasitoid & Tingkat parasitisasi (\%) \\
\cline { 2 - 3 } Padi & Telenomus sp. & 29,54 \\
& Tetrastichus sp. & 13,02 \\
& Trichogramma japonicum & 2,05 \\
Jagung & Trichogrammatoidea sp. & 29,07 \\
Kubis & Trichogramma chilotrae & 1,67 \\
\hline
\end{tabular}

Tabel 5 Indeks keanekaragaman spesies parasitoid telur lepidoptera pada tanaman padi di berbagai lokasi di Kabupaten Solok

\begin{tabular}{lc}
\hline \multicolumn{1}{c}{ Daerah sampel } & Indeks keanekaragaman \\
\hline Talang 1 & 0,47 \\
Talang 2 & 0,63 \\
Jawi-jawi 1 & 0,56 \\
Jawi-jawi 2 & 0,51 \\
Rata-rata & 0,54 \\
\hline
\end{tabular}


Tabel 6 Tingkat parasitisasi parasitoid Trichogrammatoidea sp. pada telur hama $H$. armigera pada tanaman jagung di berbagai lokasi di Kabupaten Solok

\begin{tabular}{lc}
\multicolumn{1}{c}{ Daerah sampel } & Tingkat parasitisasi (\%) \\
\hline Talang 1 & 25,00 \\
Talang 2 & 33,93 \\
Koto Gaek 1 & 25,53 \\
Koto Gaek 2 & 31,82 \\
Rata-rata & 29,07 \\
\hline
\end{tabular}

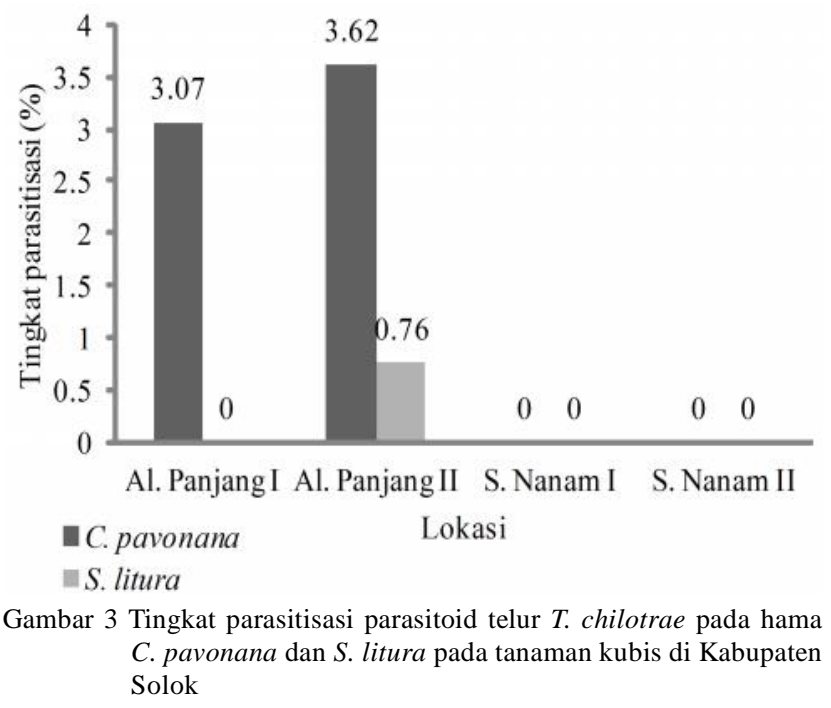

Parasitisasi-parasitoid T. chilotrae pada C. pavonana berkisar dari 3,07-3,62\% yang tergolong sangat rendah. Begitu juga pada S. litura parasitisasi hanya 0,76\% (Gambar 3). Kajian yang dilakukan oleh Hidayat et al. (1999) di Jawa menemukan spesies Trichogramma armigera yang menginfeksi telur $C$. pavonana yang berbeda dari yang ditemukan di Solok. Hal ini menunjukkan bahwa perbedaan lokasi dapat menyebabkan berbedanya jenis parasitoid yang ditemukan.

Bila diperhatikan secara keseluruhan, tingkat parasitisasi parasitoid telur famili Trichogrammatidae sangat rendah, bahkan pada tanaman tomat tidak ditemukan parasitoid telur. Kecuali pada tanaman jagung tingkat parasitisasi mencapai $29,07 \%$. Hal ini sangat erat hubungannya dengan penggunaan pestisida. Pestisida sangat berbahaya terhadap musuh alami khususnya parasitoid Trichogrammatidae. Apalagi dengan ukuran tubuhnya yang sangat kecil, Trichogrammatidae sp. sangat rentan terhadap pestisida. Hal ini terlihat pada tanaman padi dan kubis yang disemprot pestisida, tingkat parasitisasi Trichogrammatidae sp. sangat rendah. Pada tanaman tomat penggunaan pestisida sangat intensif sehingga menekan populasi hama sangat rendah yang mengakibatkan parasitoid tidak mampu menemukan inangnya, atau akibat pengaruh langsung pestisida yang dapat membunuh parasitoid. Kemudian pada tanaman jagung yang jarang atau sama sekali tidak disemprot pestisida, tingkat parasitisasi mencapai $29,07 \%$. Pada kajian yang sama dilakukan sebelumnya di Tanah Datar, juga tidak ditemui parasitoid telur pada $H$. armigera pada tomat (Hidrayani et al. 2007). Penyemprotan insektisida pada tanaman kentang, nyata menurunkan populasi parasitoid penggorok daun (Hidrayani 2003; Hidrayani et al. 2005). Parasitoid pada umumnya lebih rentan terhadap insektisida dibandingkan inangnya disebabkan oleh ketidakmampuan parasitoid tersebut mendetoksifikasi insektisida (Pedigo 1991). Insektisida juga dapat membunuh parasitoid secara langsung pada saat diaplikasikan atau karena kontak dengan residu pestisida yang terdapat pada daun saat imago betina parasitoid mencari inang (Hidrayani 2003). Selain akibat pestisida, kemungkinan rendahnya parasitoid yang ditemukan disebabkan oleh rendahnya populasi inang. Vinson (1984) menyatakan bahwa kerapatan inang yang tinggi menyebabkan mudahnya inang ditemukan oleh parasitoid, sehingga dapat meningkatnya jumlah inang yang terparasit. Ditambahkan oleh Papaj (2001) reproduksi parasitoid sangat dipengaruhi oleh keberadaan inangnya, dan sangat diperlukan untuk kelangsungan hidup parasitoid.

\section{SIMPULAN}

Terdapat tiga spesies parasitoid telur pada tanaman padi yaitu Telenomus sp., Tetrastichus sp., dan Trichogramma japonicum yang menginfeksi telur hama Scirpophaga incertulas dan Hesperidae. Satu spesies parasitiod telur pada tanaman jagung yaitu Trichogrammatoidea sp. yang menginfeksi telur Helicoverpa armigera, dan satu spesies pada tanaman kubis yaitu Trichogramma chilotrae yang menginfeksi hama Crocidolomia pavonana dan Spodoptera litura. Tingkat parasitisasi Telenomus sp., Tetrastichus sp., Trichogramma japonicum, Trichogrammatoidea sp., dan Trichogramma chilotrae berturut-turut adalah 29,54; 13,02; 2,05; 29,07; dan 1,67\%. Keanekaragaman spesies parasitoid telur pada tanaman padi dari berbagai daerah di Kabupaten Solok lebih kurang sama dengan indeks keanekaragaman spesies berkisar dari 0,47-0,63.

\section{UCAPAN TERIMA KASIH}

Penulis mengucapkan terima kasih terutama kepada DIKTI atas sebagian dana yang diberikan untuk pelaksanaan penelitian dengan No. Kontrak: 005/SP3/PP/DP2M/II/2006. Terima kasih juga ditujukan kepada saudara Adha Sari, SP 
dan Dra. Netty Yuliarti, MS atas bantuannya dalam mengidentifikasi parasitoid.

\section{DAFTAR PUSTAKA}

Ahmad, S., Ashfaq, M., Hassan, M \& Sahi, S.T. 2012. Potential of parasitoid Trichogramma chilonis (Ishii) (Hymenoptera: Trichogrammatidae) against the sugarcane stem borer, Chilo infuscatellus (Lepidoptera: Pyralidae) under field condition. Int. J. Biodiversity and Conservation 4(1): 36-38.

Ali, M., Nurdin, F \& Harnas, J. 1997. Penggunaan pestisida pada tanaman bawang merah, kentang dan kubis di Alahan Panjang, Sumatera Barat. Seminar Tantangan Entomologi Abad XXI. Bogor, 8 Januari 1997.

Buchori, D., Hidayat, P., Kartosuwondo, U., Nurmansyah, A \& Meilin, A. 2002. Dinamika interaksi antara parasitoid trichogrammatidae dan inangnya : faktor-faktor yang berpengaruh terhadap kualitas trichogrammatidae sebagai agen pengendalian hayati. Laporan penelitian Hibah Bersaing perguruan Tinggi VII/3.

Buchori, D., Meilin,A., Hidayat, P \& Sahari, B. 2010. Species distribution of Trichogramma and Trichogrammatoidea genus (Trichogrammatoidea:Hymenoptea) in Java. $J$. ISSAAS 16(1): 83-96.

Budiman, H. 2004. Eksplorasi hama pengorok daun Liriomyza spp (Diptera; Agromyzidae) dan parasitoidnya pada pertanaman kubis Brassica oleraceae Linneus di Kec. Lembah Gumanti Kab. Solok. Skripsi. Universitas Andalas. Padang.

Hidayat, P., Buchori, D \& Meilin, A. 1999. Ekplorasi dan identifikasi beberapa spesies trichogrammatidae dari berbagai daerah di Jawa. Prosiding Seminar Pengendalian Hayati. Yokyakarta, Juni. 1999.

Hidrayani. 2003. Hemiptarsenus varicornis (Girault) Hymenoptera: Eulophidae, parasitoid Liriomyza huidobrensis (Blanchrd)(Diptera: Agromyzidae): Biologi dan tanggap fungsional, serta pengaruh jenis tumbuhan inang dan aplikasi insektisida. Disertasi. Bogor: Institut Pertanian Bogor.

Hidrayani, Purnomo, Rauf,A., Ridland, P.M \& HoffmanA.A. 2005. Pesticide applications on Java potato fields are ineffective in controlling leafminers, and have antagonistic effects on natural enemies of leafminers. Int. J. Pest Manage 51(3): 181-187.

Hidrayani., Syam, U \& Fajri, M. 2006. Kajian parasitoid serangga hama tanaman kubis bunga (Brassica oleraceae L. var. Botrytis L.) pada pertanaman yang diaplikasi dan tanpa insektisida. Laporan SP4.

Hidrayani, Yaherwandi \& Sari, W. 2007. Keragaman spesies parasitoid telur pada tanaman padi, jagung, dan tomat di Kabupaten Tanah Datar. Manggaro. Jurnal Pengelolaan Hama Dan Penyakit Tumbuhan 8(1): 17-24.
Kalshoven, L.G.E. 1981. The pest of crops in Indonesia. Revised and Translated by Van der Laan. PT. Ichtiar Baru van Hoeve. Jakarta.

Krebs, C.J. 1999. Ecological Metodology. $2^{\text {nd }}$ ed. New York: An imprint of Addison Wesley Longman, Inc.

Mandour, N.S, Sarban,A.A \&Atwa, D.H. 2012. The integration between Trichogramma evanescens West. (Hymenoptera: Trichogrammatidae) and selected bioinsecticides for controlling the potato tuber moth phthorimaea operculella (Zell.)(Lepidoptera : Gelechiidae) of stored potatoes. $J$. Plant. Protection Res 52(1): 40-46.

Nurtiati. 1991. Kemampuan dan perilaku memarasit Trichogrammatidae bactrae Nagaraja (Hymenoptera : Trichogrammatidae) pada telur Plutella xylostella Linneus (Lepidoptera: Yponometidae). Tesis. Institut Pertanian Bogor.

Pabbage, M.S \& Tandiabang, J. 2007. Parasitasi Trichogramma evanescens Westwood (Hymenoptera: Trichogrammatidae) pada berbagai tingkat populasi dan generasi biakan parasitoid terhadap telur penggerek batang jagung Ostrinia furnacalis Guenee. Agritrop 26(1): 41-50.

Papaj, D.R. 2001. Ovarian dynamics and host use. Annu. Rev. Entomol 45: 423-448.

Pedigo, L.P. 1991. Entomologi and Pest Management. New York: Mac Millan Publishing Company.

Pracaya. 1999. Hama dan Penyakit Tanaman. Jakarta: Penebar Swadaya.

Rusli. 2002. Inventarisasi penggunaan pestisida oleh petani kubis di Kecamatan Lembah Gumanti, Kabupaten Solok. Jurnal Stigma X(4): 344-346.

Sastrosiswojo, S. 1996. Biological control of the diamond back moth in IPM systems. Case study from Asia. BCPC Symposium Proceedings No.67 : Biological Control Introduction.

Setiawati, W. 1991. Kehilangan hasil buah tomat akibat serangan Heliothis armigera Hubn. Bull. Penel. Hort 19(4): 14-17.

Untung, K. 1993. Pengantar Pengelolaan Hama terpadu. Gadjah Mada: University Press.

Vinson, S.B. 1984. Behavioral Chemical in The Augmentation. In. Biological Control by Augmentation of Natural Enemy. Chapman and Hall Ltd.

Yaherwandi. 2005. Keanekaragaman Hymenoptera parasitoid pada beberapa tipe lanskap pertanian di Daerah Aliran Sungai (DAS) Cianjur Kabupaten Cianjur Jawa Barat. Disertasi. Bogor: Sekolah Pascasarjana Institut Pertanian Bogor.

Yuliarti, N. 2002. Karakter morfologi dan molekular parasitoid telur, Telenomus spp (Hymenoptera: Scelionidae) dari beberapa daerah di Jawa. Tesis. Bogor: Program Pascasarjana IPB. 